\title{
Conceito de Estado
}

1) - Fallo perante cultores do direito, que conhecem a longa, a interminavel controversia de philosophos, juristas e sociologos a respeito da ideologia politica do Estado; o que disseram Platão, Aristoteles, Cicero, São Thomaz, Dante; as opulentas literaturas modernas, na Allemanha, França, Italia, Hespanha, America do Norte; e os nossos tratadistas, que depois da Republica, se têm avantajado pelo numero e pelo brilho. Por isso, em vez de uma dissertação critica, aliás deslocada, e, forçosamente, incompleta, dada a cópia de escriptores notaveis sobre o assumpto, prefiro expôr o que do ensino desses mestres pôde colher e organizar o meu espirito, apparelhado por outros estudos, que o fazem vêr, no phenomeno politico, um momento particular da evolução cosmica, depois de attingir a phase social, e para a qual as doutrinas são tentativas para alcançar a verdade, que jamais se devem nepellir in limine, por infundadas, que nos pareçam. Haverá sempre um raio de luz a aproveitar; ou será a nossa incapacidade perceptiva que lhes dará apparencia de infundadas.

2) - Comecemos por distinguir a sociedade do Estado. A sociedade é formação natural da vida super-organica, tomada a palavra na sua accepção mais geral de aggragado humano permanente, constituido por condições historicas e por necessidades e interesses, tanto de ordem moral quanto de ordem economica. As relações de familia, a industria, o 
commercio, as artes, a religião, os costumes, a moral são manifestações de vida da sociedade. Estas manifestações, porém, cada vez mais variadas, exigem, para que se possam conservar, desenvolver e harmonisar, a creação de uma energia de outra ordem, que as defenda, lhes assegure o campo, que lhes é proprio, as dirija, e até as possa estimular, em dadas circumstancias. Poderia aqui fallar no apparelho regulador do organismo social, para seguir a lição de Spencer (1). Prefiro, entretanto, dizer que essa energia, criada pela vida social para a sua propria segurança e desenvolvimento, é o direito; e que é a necessidade de regular o funccionamento do direito, tanto nas relações internas, entre classes e individuos, quanto nas externas, entre organismos sociaes superiores, que, por sua vez gera o Estado, con o seu apparelhamento muito simples nas origens da humanidade, e, hoje, extremamente complicado.

Um nosso sociologo, o Professor Fernando Antunes, da Faculdade de Direito de Porto Alegre, em livro muito estimavel, debate este assumpto, e, repellindo a opinião de varios pensadores, sustenta que, no rigor da linguagem sociologica, sociedade e Estado são expressões equipolente, são conceitos identicos (2). Teria pesar de não vêr ao meu lado o publicista riognandense do sul; mas não me parece que estejamos tão distanciados um do outros, quanto, á primeira vista, seriamos levados a suppôr, visto como a identidade, que elle affirma, relativamente aos dous conceitos, funda-se no facto de não existir sociedade civil sem Estado, e eu reconheço que a sociedade, desde que attinja certo gráo de cultura, ha de viver, necessariamente, sob o tegumento do Estado. Abro apenas excepção para tres organizações sociaes, de genero aliás differente da que agora estou considerando.

(1) Principes de sociologie, trad. Cazellas et Gerschel, Paris, 1882, II, Cap. IX.

(2) O Estado, em face da sociologia, da politica e do Direito Publico, Porto Alegre, 1920, pagina 40. 
Entre os Estados formaram-se duas aggnemiações: uma surgiu da guerra mundial. E' mais compreherısiva, porém, repousa em base menos solida, por se ter formado em uma situação anormal, dos povos, e resentir-se dessa circumstancia. E' a Sociedade das Nações. A outra é a União dos Estados americanos, que se vem preparando, desde o Congresso do Panam convocado por Simão Bolivar, como expressão natural do pan-americanismo, ou solidariedade dos povos do nosso continente, e tem por orgams principaes a Conferencia Internacional Americana e a União Pan-Americana, sob a direcção de um Conselho.

Ambas ainda não attingiram á necessaria consistencia; mas, por isso mesmo que solicitadas pela evolução social humana, a desenvolver curvas cada vez mais amplas, hão de affirmar-se, definitivamente, e por fim, unir-se num só corpo.

Uma terceira fórma de sociedade humana, que excede ao ambito do Estado, é a dos individuos, que, embora espalhados pelo mundo e pertencendo a povos differentes, se acham vinculados por fortissimos interesses economicos e moraes.

As duas primeiras constituem o campo do Direito $\mathrm{Pu}$ blico Internacional, o dos povos cultos em geral e o dos povos americanos.

A ultima é regida pelo Direito Internacional Privado acceito pelas diversas naçôes, mas cuja construcção presuppõe relações, que se travam além das suas fronteiras.

Afastadas essas excepções, a sociedade humana mantem-se, necessariamente, dentro da organização politico-juridica do Estado.

3 - Ainda que não devamos confundir a sociedade com o Estado, não podemos desconhecer que, distribuindo-se a sociedade humana em aggregados nacionaes, é o Estado que organiza esses aggregados, por meio de appanelhos adequados, e, pois, nos será permittido definil-o um agrupamento humano, estabelecido em determinado ter- 
ritorio e submettido a um poder soberano, que lhe dá unidade organica.

Nesta definição, destacam-se os elementos constitutivos da idéa de Estado:

a) O agrupamento humano, que é a mesma sociedade, o povo, ou a nação, segundo consideramos o aggregado social como um systema de forças, economicas, intellectuaes e moraes, abstrahindo do apparelho politico-juridico; o complexo dos individuos entre si vinculados pela tradição, usos, costumes tendencias, aspirações communs; ou esse conjunto de individuos, constituindo uma unidade por suas condições historicas e por sua organização politica.

A idéa de sociedade é sociologica; a de povo, ethnologica; e a de nação é historico-politica. Não aprofundarei essas distincções, acompanhando argutos pensadores allemães; mas devo affirmar que não são meramente escolasticas. Além de corresponderem a realidades, assignalando modalidades ou expressões da vida collectiva, fornecem luzes para a verdadeira theoria do Estado.

b) O territorio, assento geographico do Estado. Para o povo é a patria, a terra dos antepassados, o ambiente, onde lhe decorreu a vida, sorriu no berço aos afagos maternos, lutou, soffreu, e sente que é uma parte da sua alma. Para a nação, é a sua residencia inviolavel e sagrada, o theatro onde se fixou, cresceu, desenvolveu e a que se prende indissoluvelmente.

c) O poder soberano é a força que, pelo direito e a politica, equilibra, unifica, disciplina e dirige as outras forcas sociaes e os individuos. Propriedade fundamental do Estado, a soberania o distingue de outras corporações quaesquer.

E' ocioso indagar se essa autoridade suprema, essa força, que domina as outras forças dentro do paiz, tem a sua origem no povo, ou é a nação que a possue, como attributo essencial. 
Falla-se em povo soberano e em soberania nacional, expressão consagrada em nossa Constituição republicana, segundo a qual o Poder Legislativo, o Executivo e o Judiciario são orgams da soberania nacional. A Constituição do Estado Federal (Reich) allemão proclama: O Poder $\mathrm{Pu}$ blico emana do povo.

Quando dizemos que o povo é soberano, queremos affirmar que, nas democracias, á massa da população nacional e não a um grupo, uma familia ou uma casta, cabe assumir, por meio de seus representantes, a direcção dos negocios publicos; sustentamos idéa opposta á de GumPlowicz, adoptada por Duguit, de que ha, fatalmente, nas organizações politicas, dominantes e dominados, não podendo as mais aperfeiçoadas democracias fugir a essa contingencia (3).

Por soberania nacional entendemos a autoridade superior, que synthetisa, politicamente, e segundo os preceitos do direito, a energia coactiva do aggregado nacional.

Não ha ahi nenhuma idéa metaphysica, senão o reconhecimento de um facto; não ha ahi "a mystificação oppressiva" assignalada por Augusto Comte (4).

Soberania é autoridade suprema, necessaria á ordem social, dentro da qual tem de viver a nação, ou o povo. Quem a exerce é o Estado por seus orgams ou poderes, por que o Estado é a fórma pela qual a sociedade, a nação, ou o povo, se organiza, politica e juridicamente.

d) Essa concentração do poder supremo no Estado é que lhe dá personalidade, em virtude da qual exerce direitos, internamente, em relação aos individuos e ás classes, que compõem a sociedade, e, externamente, em frente aos outros Estados.

(3) Gumplowicz, La lutte des races, pag. 235; Duguit, Droit Constitutional, II, pag. 13-16, da segunda edição.

(4) Système de politique positive. IV, app., pag. 103. 
Esta idéa simplissima, que resulta dos factos diariamente observados, é diversamente explicada pelos autores, e até repellida por alguns, offerecendo aos estudiosos do Direito Publico uma lamentavel confusão, aquillo que PoSADA denomina crise sociologica, psychologica e juridica do Estado (5). Mas, se a existencia da collectividade, que chamamos Nação, é innegavel, e se a Nação se organiza, politica e juridicamente, pelo Estado, a personalidade deste é da mesma natureza, no campo do direito, que a do individuo, sendo apenas mais extensa. Não é necessario que ao Estado corresponda uma entidade physica, palpavel, para que se lhe reconheça personalidade. As outras pessôas juridicas tambem não são entidades physicas, e o proprio individuo não é, como ser biologico ou corpo material. que possue o attributo de pessôa. E' como elemento da sociedade, que, por sua vez, não tem existencia material. E' um ser de ordem politico-juridica.

4 - Segundo a evolução social, o progresso humano, do ponto de vista da industria, da sciencia e da ethica, o Estado se tem modificado, porque tem de reflectir a physionomia da sociedade pela qual e para a qual foi creado. Dahi as fórmas de governo, que, variando no desdobrar da cixilisação, quebraram, afinal, o quadro descripto por ArisTOTELES (6), rigorosamente exacto em seu tempo, mas hoje sem actualidade para exprimir, com verdade, a correlação necessaria entre a vida social e a organização da autoridade, que preside á sua conservação e ao seu desenvolvimento.

Das fórmas normaes, aristotelicas, subsiste a democracia, que, aliás, o grande philosopho, chamava politeia, ou republica, reservando o vocabulo democracia para uma das fórmas anormaes, o governo da multidão.

(5) Un libro sobre el Estado. Madrid, 1904, pag. 33.

(6) La politique - trad. Thurot, livro III, Cap. V. 
Isso mesmo jả indica ser outra a concepção moderna das fórmas de Estado ou de governo. As outras fórmas normaes são a realeza ou monarchia e a aristocracia. Esta ultima não existe no Occidente, como fórma de Estado, e a primeira perdeu a sua feição propria, penetrada, como se acha, por principios contrarios á sua essencia.

Infelizmente, a perturbação dos espiritos, na hora amarga, que vamos atravessando, tem feito surgir, como sobrevivencias malsãs de eras recalcadas nos desvãos da historia, anormalidades que, em parte, desviam da rota progressiva as forças que organizam a vida social. Sob o pretexto de promover o bem commum, destróe-se a liberdade, e sacrifica-se a ethica.

5 - Defronta o mundo, actualmente, as seguintes fórmas de Estado: o fascismo, o bolchevismo e a democracia representativa, cuja, expressão mais pura é a Republica Federativa.

O estado fascista é a absorpção do individuo pelo Estado; a tutela vigorosa das energias naturaes da sociedade pelo governo; o predominio, sem contraste, da autoridade, que se espera seja bem intencionada; a suppressão da liberdade, como perturbadora da harmonia social. "Tudo pelo Estado; nada fóra do Estado; nada contra o Estado"! Exclama a theoria do fascio.

Essa concepção inverte a ordem natural das idéas. A sociedade surgiu para tornar possivel a coexistencia dos homens, como o Estado foi criado para manter a sociedade, e permittir o seu desenvolvimento. A doutrina fascista, porém, arvorando o Estado em supremo regulador da actividade e das instituições, confere-lhe a responsabilidade da vida commum, “á qual dá fórma e orientação, á qual assignala um typo a realizar, assumindo aquella fórma essencial, que o seu povo tem e deve desenvolver, na realidade historica do Universo" (7).

(7) Ugo Redanó, da Universidade de Roma, na Revista Internacional de Filosofia del Diritto, 1928, pag. 325. 
A sociedade sem o Estado, concebe-se; o Estado, sem a sociedade, seria um tecto no ar, sem paredes ou pilastras, onde se apoiasse; portanto, é a sociedade, que deve dar fórma e orientação ao Estado e não este a ella.

A marcha da civilisação, no dominio, que agora estamos considerando, é no sentido do maior valor do homem, de mais desenvolvido senso moral, de mais lucida consciencia dos direitos, que, por sua vez, mais avultam na téla social. Correspondentemente, se retráe a autoridade publica, por se tornar desnecessaria a sua intervenção, em muitos casos, que anteriormente a exigiam. O Estado absorvente não é, consequentemente, producto natural da evolução politico-juridica.

A concepção bolchevista do Estado é a dictadura do proletariado, que se substitue ao que Lenin denominou "machina de oppressão do proletariado pela burguezia" (8).

Nasceu este regimen de uma reacção contra o absolutismo czarista; por isso, deu a predominancia, na direcção dos negocios publicos, aos que formavam a classe esplorada, dos trabalhadores, com exclusão dos capitalistas e proprietarios. Somente os que trabalham podem governar, declara-se.

Mudam-se, apenas, os papeis: os dominados passam a ser dominantes, com rigor maior no exclusivismo; porque, no chamado Estado burguez, os operarios exercem direitos politicos, e nas republicas sovieticas, os burguezes não são eleitores nem elegiveis (9). Ainda que se trate de uma construcção provisoria, emquanto não se opera o pleno advento do communismo, não a póde approvar a justiça. E desde que o communismo dispensará, no futuro, os apparelhos gastos do Estado, parece que seria melhor supprimir, desde logo, o Estado, onde se implantasse o novo regimen, do que adoptar sobre base evidentemente injusta.

(8) Apud Stefan Yanneff, La Constitution de l'Unions des Republiques socialistes sovietiques, Paris, 1926, pag. 41.

(9) Stefan Yaneff, op. cit. pag. 45. 
Aliás, a fórma de governo implantada na Russia é uma Federação de Republicas socialistas sovieticas, nucleo inicial, que se propõe, com a suppressão das classes sociaes e com a livre formação de povos, a estender-se por todo o orbe, sem eliminar a idéa de soberania, que é plena para a União e limitada para as Republicas federadas; conservando os orgams do Estado moderno, ainda que differentemente distribuidos; e eliminada a divisão dos poderes, que se substitue pela extensão varia, conferida aos que as exercem.

Afigura-se-me essa concepção da vida social, politicamente organizada, producto de mentalidade estranha á cultura greco-romana, porque não se baseia em idéas, que constituem acquisições definitivas da sociologia e do direito.

No meu sentir, a fórma de Estado, que melhor póde attender ao bem geral, á necessidade de justiça nas relações humanas, á liberdade civil e politica, é a Republica de mocratica federativa, essa mesma que uma geração de brasileiros, na qual, bellamente, se transfudira a alma da patria, soube insculpir na Constituição de 24 de Fevereiro de 1891.

6 - Se procurarmos apprehender, atravez da evolução humana, qual a fórma de Estado, que corresponde aos sentimentos mais profundos do homem e ás necessidades vitaes de uma sociedade culta, acharemos que é a democracia. O que a humanidade aspira, para cada grupo social, é uma organização politica, em que o grupo se reconheça, realmente, representado, e isto somente se alcança pela democracia representativa; é uma organização politica, na qual se realize, de modo mais completo, a justiça e um tal desideratum sómente pela democracia representativa é possivel satisfazer; é uma organização politica, em que as actividades honestas se possam, livremente, desenvolver, sem outras limitações, que não sejam as resultantes da propria coexistencia, as quaes a moral e o direito reflectem para que sejam respeitadas. 
Eis ahi: - a evolução social nos conduz para uma democracia representativa, em que o povo a si mesmo se governa, delegando poderes para isso aos que reputa mais capazes, para realizar a justiça, assegurar a liberdade disciplinada pelo direito e pela moral e fomentar o bem commum.

Vacherot dizia que a unica verdade em politica era a justiça, da mesma fórma que o bello é a unica verdade na arte e o honesto é a unica verdade na moral (10). E' um autor hoje esquecido, que os annos e as idéas dominantes afastaram de nós, porém, que seduzia ainda o espirito dos que passaram pelas Faculdades de Direito, quando cursei a do Recife, e no qual ainda podemos colher muitas idéas sãs.

Não será a justiça a verdade unica da politica, scientificamente considerada; mas é uma idéa fundamental para ella, porque é uma indeclinavel necessidade das agremiações de homens cultos e dignos.

Foi com inteira razão e applausos dos que têm o verdadeiro sentimento republicano, que o egregio Presidente do Instituto da Ordem dos Advogados Brasileiros, affirmou que a Constituição de 1891 era a melhor das nossas leis, principalmente por nos ter dado estas duas "garantias, definitivas e inestimaveis do progresso dos Estados e dos direitos do individuo, o federalismo e o judiciarismo" (11).

No judiciarismo está a preeminencia da justiça. Sem ella, não ha regimen democratico. $E$ porque é necessidade vital nas democracias, dá-se preponderancia aos orgams, que a têm de realizar, praticamente.

Justiça é idéa mais alta do que direito, porque envolve o influxo da ethica; aliás, o ethicismo tambem penetra o direito, para lhe dar maleabilidade e benefica repercussão nas consciencias. Quando fallamos de Justiça imaginamos o imperio do direito applicado com intelligencia e

(10) La democratie, 1860, pag. 22.

(11) Levi Carneiro, Federalismo e Judiciarismo, pag. 22. 
serenidade, não somente o direito legal, mas o direito justo, de que nos falla Stanler.

Outro principio essencial á democracia é o da liberdade, que o direito disciplina, respeitando-a, porque ella é a expressão mais alta da personalidade humana, e é, ao mesmo tempo, força propulsiva do progresso social, tanto o moral quanto o economico.

Disse Hegel que a historia universal é a historia da liberdade.

Realmente o progresso humano, do ponto de vista politico, se tem realizado no sentido de dar maior valor ao homem, para que a sua actividade melhor se possa expandir, no interesse da sociedade. E é logico. A sociedade tem por elementos constitutivos os individuos: se os comprime e deprime ella mesma se estiola e desorganiza.

7 - A democracia, regimen de egualdade dos cidadãos, de executivo eleito temporario, responsavel, necessita de alliar-se á Federação para prosperar, em nações de extensão territorial mais ou menos consideravel.

Raoul de la Grasserie, em livro de alto cunho scientifico, demonstrou que o federalismo, além de ser a fórma de Estado mais adequada ao desenvolvimento material e moral dos povos, é a resultante necessaria das forças organicas da sociedade humana (12).

Entre nós, essas razões theoricas se tornam exigencias praticas, por força das condições historicas e da fatalidade geographica. O Brasil colonisado por um systema dispersivo, que a monarchia unificou, felizmente, já no segundo imperio anceiava por se desafogar da centralisação, pedindo mais amplitude para os governos provinciaes, do que lhes ensanchava o Acto Addicional. Mas a descentralisação, então necessaria ao progresso do paiz, tenderia a destruir o principio monarchico. E' que findara a missão historica da monarchia. Para dar satisfação plena ás justas

(12) L'état fédératif, 1897. 
exigencias de uma população sedenta de progresso, mas espalhada pela vasta extensão do paiz, e tendo necessidades particulares, proprias, era forçoso manter a unidade, que a monarchia consolidara, mas proporcionar, a cada região, faculdade para se reger de accôrdo com os seus interesses peculiares, e desenvolver as suas energias productivas, do modo mais consentaneo.

Surgiu, então, a Republica Federativa, cuja applicação tem encontrado algumas difficuldades, apesar de ter apparecido como producto espontaneo da evolução nacional. Em parte, são devidos esses ambaraços á natureza delicada do regimen. Quanto mais perfeita a machina maior habilidade exige do technico, incumbido de dirigil-a, quando sobrevem qualquer desarranjo. Mais vezes, porém, o federalismo parece funccionar mal, porque o movem não pela força, que lhe é immanente, isto é, o consorcio das aspirações locaes e da liberdade individual, com as directrizes constitucionaes da União; e sim por interesses outros de criterio individual ou partidario.

Por isso, encerro estas considerações, fazendo um appello aos juristas, invocando o seu patriotismo, o seu amor ao direito, a sua cultura, para que desenvolvam energias no sentido de fazer penetrar, na alma do povo, o sentimento da democracia liberal federativa, orientada pela Justiça. A Constituição da Republica é uma biblia, que deve ser derramada por todos os recantos do paiz, lida com uncção religiosa, esclarecida com intelligencia, bôa vontade e carinho. O que lhe trouxe de máo a reforma de 1926 o tempo corrigirá. O essencial é nos convencermos de que a geração, que organizou a Republica, soube exprimir as aspirações do povo brasileiro, e o dotou com uma Constituição que bem applicada lhe póde assegurar o maximo desenvolvimento economico, moral e politico.

Certo ella não será a perfeição absoluta; mas é sufficiente para tornar realidade o lemma de ordem e progresso inscripto na bandeira, e permittir a ascenção para 
os ideaes, que a vida humana fôr criando, como antevisões do futuro.

A synthese da politica republicana democratica é Liberdade dentro da ordem, egualdade em face da lei, e justiça garantindo á ordem, á liberdade e á egualdade.

A nossa Constituição de 1891 moldou-se por esses principios. Olvidaram-n'os, talvez os homens.

Fazei-os resplandecer no firmamento politico do Brasil.

DR. CLOVIS BEVILAQUA

(Professor, em disponibilidade, da Faculdade de Direito de Recife). 